\title{
Thio Analogs of Pyrimidine Bases: Synthesis, Spectroscopic Study, and In Silico Biological Activity Evaluation of New 2-o-(m- and $p$-)Chlorobenzylthio-6-Methyl-5- Piperidino- (Morpholino-)Methyluracils
}

\author{
Tomasz Pospieszny, Marcin Szymankiewicz, and Elżbieta Wyrzykiewicz \\ Faculty of Chemistry, Adam Mickiewicz University in Poznań, Grunwaldzka 6, 60-780 Poznań, Poland \\ Correspondence should be addressed to Tomasz Pospieszny, tposp@amu.edu.pl
}

Received 24 January 2011; Accepted 3 March 2011

Academic Editor: A. K. Chatterjee

Copyright (C) 2011 Tomasz Pospieszny et al. This is an open access article distributed under the Creative Commons Attribution License, which permits unrestricted use, distribution, and reproduction in any medium, provided the original work is properly cited.

Six new 2-o-( $m$ - and $p$-)chlorobenzylthio-6-methyl-5-piperidino-(or morpholino-) methyluracils have been prepared. The structures of these compounds were confirmed by spectroscopic (FT-IR, UV-Vis, ${ }^{1} \mathrm{H}$ NMR, ${ }^{13} \mathrm{C}$ NMR, and HMBC) and elemental analyses. Estimation of pharmacotherapeutic potential has been made for synthesized compounds on the basis of prediction of activity spectra for substances (PASS).

\section{Introduction}

Thio derivatives of pyrimidine bases have remarkably contributed to biological and medicinal chemistry. Chemical modification of these compounds have led to a large number of mono- and di-S and $N$-substituted analogs showing therapeutic properties, especially antivirial, antithyroid, and antitumor activities [1-7]. The antimetabolites of 5,6dimethyluracil 5-morpholinomethyl-6-methyl-2-thiouracil [8] and 5-piperidinomethyl-6-methyl-2-thiouracil [9] have been synthesized via the Mannich reaction. However, to the best of our knowledge no work has been published on the synthesis as well as on physicochemical properties of the monochlorobenzylthio-substituted derivatives of these compounds. This fact has stimulated us to investigate the reaction of chlorobenzylation of 2thio-5-piperidinomethyl-6-methylthiouracil and 2-thio-5morpholinomethyl-6-methylthiouracil as well as the Mannich reaction of 2-o-( $m$ - and $p-)$ chlorobenzylthio-6-methylthiouracils, formaldehyde, and piperidine (or morpholine). Recently novel pharmacological action of 2,4-di-o- $(m$ - and $p$-)bromo-(chloro- and nitro-)benzylthio-5-bromouracils (and 6-methyluracils) [10] as well as disulfides of $\mathrm{N}, \mathrm{O}-(\mathrm{N}, \mathrm{N}-$ or $O, O$-)-di- and N,N,O-tri-(o-, $m$ - and $p$-)-bromobenzyl-2thiouracils [11] has been found on the basis of the computeraided drug discovery approach with the compounds program Prediction of Activity Spectra for Substances (PASS) [12-15]. Since only the structural formula of the chemical compound is necessary to obtain a PASS prediction, this approach was used in the present work. This paper deals with the synthesis and physicochemical properties of 16. Additionally, the analysis of biological activity spectra prediction for 1-6 made in this paper is a good example of in silico studies of chemical compounds.

\section{Results and Discussion}

A series of six new 2-o-( $m$ - and $p$-)chlorobenzylthio-5-piperidinomethyl-6-methyluracils 1-3 and 2-o-( $m$ - and $p-)$ chlorobenzylthio-5-morpholinomethyl-6-methyluracils 4-6 were synthesized by the reaction of 2-thio-5-piperidinomethyl-6-methyluracil or 2-thio-5-morpholinomethyl6 -methyluracil in $3 \mathrm{~N} \mathrm{NaOH}$ in methanol with $o-(m-$ and $p$-)chlorobenzyl chlorides at room temperature for $24 \mathrm{~h}$ (Scheme 1). Compounds 1, 3, 4, and 6 were also 


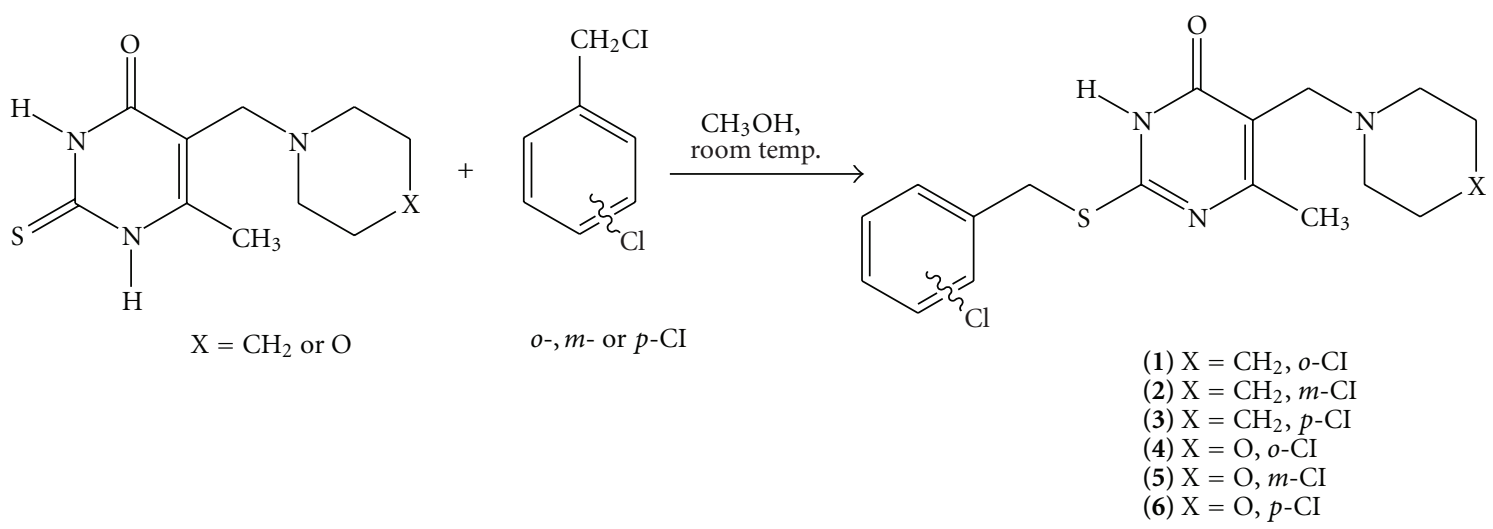

Scheme 1

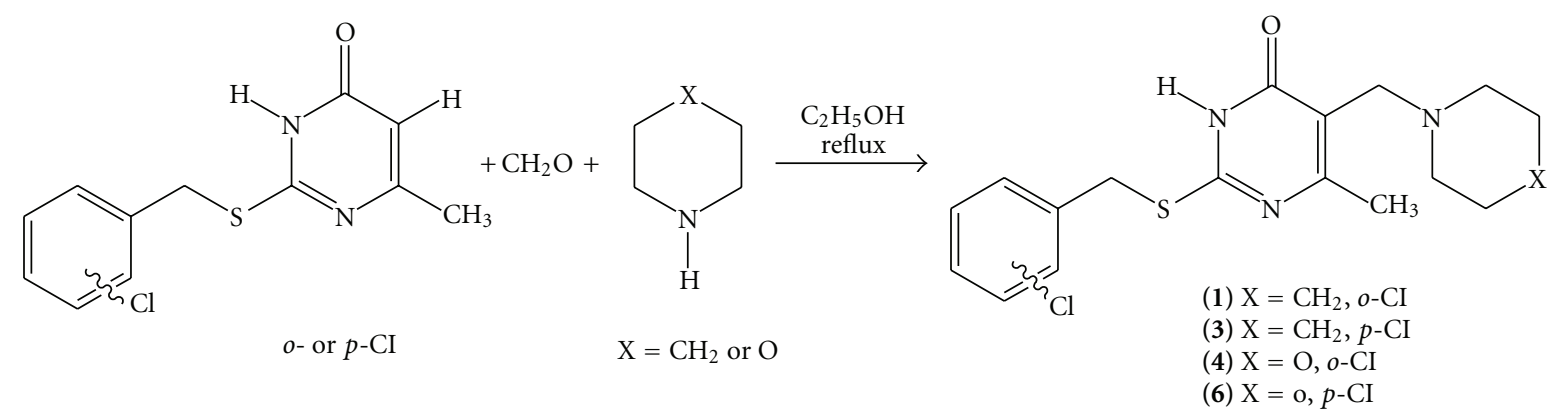

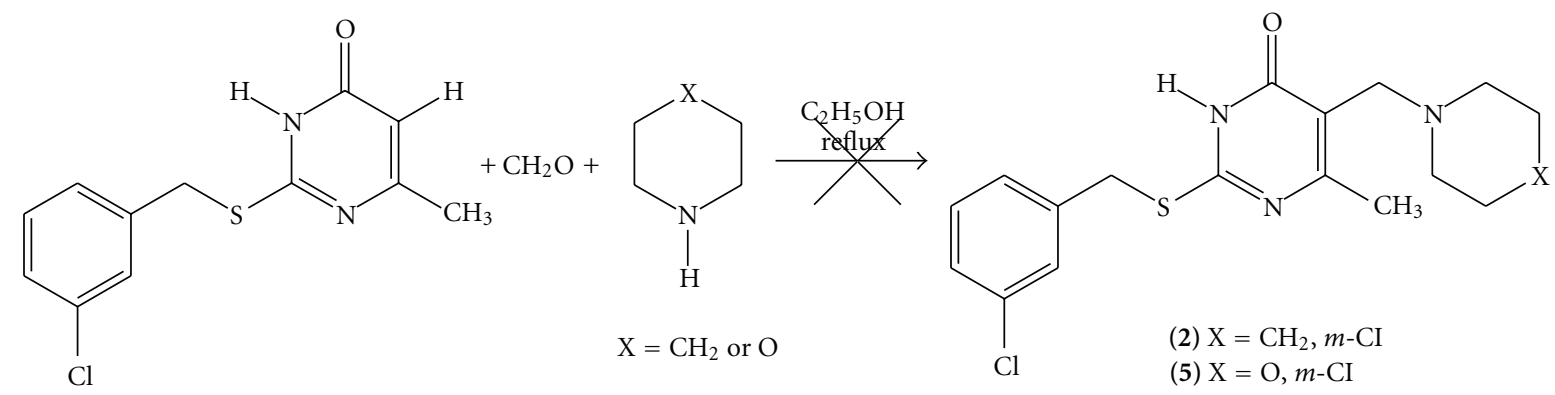

Scheme 2

produced in well-known Mannich reaction [16] from 2-o-(and $p$-)chlorobenzylthio-6-methyluracils [17] when refluxed with paraformaldehyde and piperidine (or morpholine) in ethanol (Scheme 2). Compounds 2 and 5 were not produced in the Mannich reaction of relatively soft 2-m-chlorobenzylthio-6-methyluracils with paraformaldehyde and piperidine (or morpholine) when heated in ethanol (Scheme 2$)$. The $2 o$ - $(m$ - and $p$-)chlorobenzylthiocontaining compounds $\mathbf{1 - 6}$ were confirmed by examination of their UV/Vis, FT-IR, ${ }^{1} \mathrm{H}$ NMR and ${ }^{13} \mathrm{C}$ NMR spectra (Tables 1 and 2), and HMBC (Table 3) as well as elemental analyses (Table 4).

The ${ }^{1} \mathrm{H}$ NMR and ${ }^{13} \mathrm{C}$ NMR data of $\mathbf{1 - 6}$ are given in Tables 1 and 2, respectively. Assignments of the ${ }^{1} \mathrm{H}$ $\mathrm{NMR}$ and ${ }^{13} \mathrm{C}$ NMR resonances of these compounds were deduced on the basis of the signal multiplicities and by the corrected application of two-dimensional NMR technique ${ }^{1} \mathrm{H}-{ }^{1} \mathrm{H}$ COSY and HMBC. The ${ }^{1} \mathrm{H}$ NMR spectra of $\mathbf{1 - 6}$ reveal singlets of $\mathrm{S}-\mathrm{CH}_{2}$ at $4.29-4.46 \mathrm{ppm}$. The singlets of $\mathrm{C}_{5}-$ $\mathrm{CH}_{2}$ of $1-6$ are situated at $3.28-3.58 \mathrm{ppm}$, and the singlets of $\mathrm{C}_{6}-\mathrm{CH}_{3}$ of $1-6$ are situated at $2.22-2.33 \mathrm{ppm}$, respectively.

The ${ }^{13}$ CNMR spectra of compounds $\mathbf{1 - 6}$ in $\mathrm{DMSO}_{d 6}$ showed characteristic signals in the range of 31.55-32.81 ppm and 53.04-53.71 ppm assigned to $\mathrm{S}-\mathrm{CH}_{2}$ and $\mathrm{N}-\mathrm{CH}_{2}$, respectively. The thiouracil ring exhibited signals in the range 110.01-114.71 ppm and 158.81-162.11 ppm assigned to $\mathrm{C}_{5}=\mathrm{C}_{6}$, respectively. The ${ }^{13} \mathrm{C}$ NMR spectra of compounds 1-6 showed the presence of a methyl group from the 6methyl-2-thiouracil ring at 20.90-21.30 ppm. 
TABLE 1: FT-IR, UV-Vis, and ${ }^{1} \mathrm{H}$ NMR data of compounds 1-6.

\begin{tabular}{|c|c|c|c|c|c|c|}
\hline \multirow{3}{*}{ Comp. } & \multirow{3}{*}{ UV/Vis $\left(\mathrm{CH}_{3} \mathrm{OH}\right) \lambda_{\max } \mathrm{nm}(\log \varepsilon)$} & \multicolumn{2}{|c|}{ FT-IR cm $\mathrm{cm}^{-1}(\mathrm{KBr})$} & \multicolumn{3}{|c|}{${ }^{1} \mathrm{H}$ NMR $\left(\mathrm{DMSO}_{d 6}\right) \mathrm{ppm}$} \\
\hline & & $\mathrm{S}-\mathrm{CH}_{2}(\nu)$ & $\mathrm{C}-\mathrm{Cl}(\nu)$ & $\mathrm{S}-\mathrm{CH}_{2}(\mathrm{~s})$ & $\mathrm{C}_{5}-\mathrm{CH}_{2}(\mathrm{~s})$ & $\mathrm{C}_{6}-\mathrm{CH}_{3}$ (s) \\
\hline & & $\mathrm{S}-\mathrm{CH}_{2}(\delta)$ & $\mathrm{C}-\mathrm{Cl}(\delta)$ & $\mathrm{s}-\mathrm{CH}_{2}(\mathrm{~s})$ & $\mathrm{C}_{5}-\mathrm{CH}_{2}(\mathrm{~s})$ & $\mathrm{C}_{6}-\mathrm{CH}_{3}(\mathrm{~s})$ \\
\hline \multirow{2}{*}{1} & \multirow{2}{*}{$250.0(3.03)$} & 2857.5 & 1052.5 & \multirow{2}{*}{4.39} & \multirow{2}{*}{3.58} & \multirow{2}{*}{2.23} \\
\hline & & 1447.4 & 820.3 & & & \\
\hline \multirow{2}{*}{2} & \multirow{2}{*}{$250.0(3.00)$} & 2856.8 & 1035.0 & \multirow{2}{*}{4.30} & \multirow{2}{*}{3.58} & \multirow{2}{*}{2.22} \\
\hline & & 1446.3 & 822.1 & & & \\
\hline \multirow{2}{*}{3} & \multirow{2}{*}{$249.5(2.87)$} & 2864.6 & 1055.3 & \multirow{2}{*}{4.29} & \multirow{2}{*}{3.57} & \multirow{2}{*}{2.22} \\
\hline & & 1450.9 & 819.6 & & & \\
\hline \multirow{2}{*}{4} & \multirow{2}{*}{$247.0(3.27)$} & 2852.5 & 1053.1 & \multirow{2}{*}{4.46} & \multirow{2}{*}{3.29} & \multirow{2}{*}{2.33} \\
\hline & & 1444.0 & 814.1 & & & \\
\hline \multirow{2}{*}{5} & \multirow{2}{*}{$245.5(3.34)$} & 2858.5 & 1059.6 & \multirow{2}{*}{4.36} & \multirow{2}{*}{3.29} & \multirow{2}{*}{2.31} \\
\hline & & 1456.3 & 813.0 & & & \\
\hline \multirow{2}{*}{6} & \multirow{2}{*}{$247.5(3.23)$} & 2858.8 & 1091.3 & \multirow{2}{*}{4.35} & \multirow{2}{*}{3.28} & \multirow{2}{*}{2.31} \\
\hline & & 1444.7 & 809.6 & & & \\
\hline
\end{tabular}

TABLE $2:{ }^{13} \mathrm{C}$ NMR data of compounds $\mathbf{1 - 6}$.

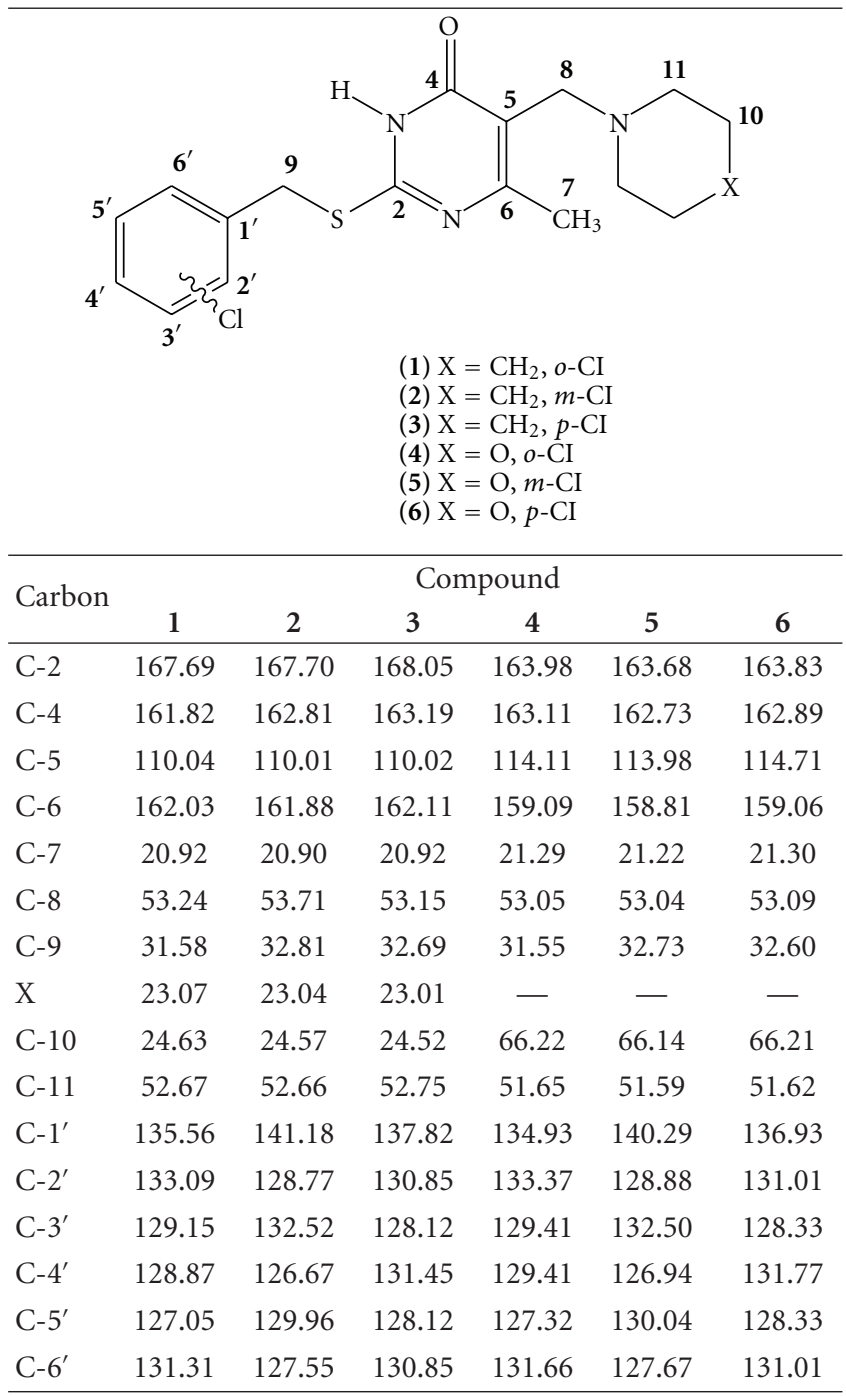

TABLE 3: The HMBC correlations between protons and carbons of compounds 1-6.

\begin{tabular}{lccc}
\hline Compound & Carbon atom & $\delta \mathrm{C}(\mathrm{ppm})$ & $\mathrm{HMBC}{ }^{1} \mathrm{H} /{ }^{13} \mathrm{C}$ \\
\hline $\mathbf{1}$ & $\mathrm{C}-2$ & 167.69 & $\mathrm{~S}-\mathrm{CH}_{2}$ \\
& $\mathrm{C}-4$ & 161.82 & $\mathrm{C}_{5}-\mathrm{CH}_{2}$ \\
& $\mathrm{C}-6$ & 162.03 & $\mathrm{C}_{6}-\mathrm{CH}_{3}$ \\
\hline \multirow{2}{*}{$\mathbf{3}$} & $\mathrm{C}-2$ & 167.70 & $\mathrm{~S}-\mathrm{CH}_{2}$ \\
& $\mathrm{C}-4$ & 162.81 & $\mathrm{C}_{5}-\mathrm{CH}_{2}$ \\
& $\mathrm{C}-6$ & 161.88 & $\mathrm{C}_{6}-\mathrm{CH}_{3}$ \\
\hline \multirow{3}{*}{$\mathbf{4}$} & $\mathrm{C}-2$ & 168.05 & $\mathrm{~S}-\mathrm{CH}_{2}$ \\
& $\mathrm{C}-4$ & 163.19 & $\mathrm{C}_{5}-\mathrm{CH}_{2}$ \\
& $\mathrm{C}-6$ & 162.11 & $\mathrm{C}_{6}-\mathrm{CH}_{3}$ \\
\hline \multirow{5}{*}{$\mathbf{5}$} & $\mathrm{C}-2$ & 163.98 & $\mathrm{~S}-\mathrm{CH}_{2}$ \\
& $\mathrm{C}-4$ & 163.11 & $\mathrm{C}_{5}-\mathrm{CH}_{2}$ \\
& $\mathrm{C}-6$ & 159.09 & $\mathrm{C}_{6}-\mathrm{CH}_{3}$ \\
\hline \multirow{6}{*}{$\mathbf{C}$} & $\mathrm{C}-2$ & 163.68 & $\mathrm{~S}-\mathrm{CH}_{2}$ \\
& $\mathrm{C}-4$ & 162.73 & $\mathrm{C}_{5}-\mathrm{CH}_{2}$ \\
& $\mathrm{C}-6$ & 158.81 & $\mathrm{C}_{6}-\mathrm{CH}_{3}$ \\
\hline
\end{tabular}

The HMBC spectrum clearly shows the connectivities of all hydrogen and carbon atoms involved, including quaternary carbons. The HMBC results allow an unequivocal assignment of $S$-substitution of benzyl group at uracil ring of 1-6 (Table 3). The HMBC experiment is conducted without ${ }^{13} \mathrm{C}$ decoupling so that correlations via one or more bond can be discerned and one-bond correlation affords double cross-peaks in the ${ }^{1} \mathrm{H}$ dimension. For compounds $1-6$ the ${ }^{1} \mathrm{H}$ NMR spectrum exhibits three singlets at 4.29-4.46, 
TABLe 4: Physical and analytical data of compounds 1-6.

\begin{tabular}{|c|c|c|c|c|c|c|c|c|c|c|}
\hline \multirow{3}{*}{ Comp. } & \multirow{3}{*}{ Formula MW } & \multirow{3}{*}{ Yield [\%] } & \multirow{3}{*}{ M.p. $\left[{ }^{\circ} \mathrm{C}\right]$} & \multirow{3}{*}{ Rf TLC* } & \multicolumn{6}{|c|}{ Analysis } \\
\hline & & & & & \multicolumn{3}{|c|}{ Calculated } & \multicolumn{3}{|c|}{ Found } \\
\hline & & & & & $\mathrm{C}$ & $\mathrm{H}$ & $\mathrm{N}$ & $\mathrm{C}$ & $\mathrm{H}$ & $\mathrm{N}$ \\
\hline 1 & $\begin{array}{c}\mathrm{C}_{18} \mathrm{H}_{22} \mathrm{~N}_{3} \mathrm{SOCl} \\
363.90\end{array}$ & 58 & $183-3$ & 0.21 & 59.12 & 5.89 & 11.55 & 59.00 & 5.60 & 11.40 \\
\hline 2 & $\begin{array}{c}\mathrm{C}_{18} \mathrm{H}_{22} \mathrm{~N}_{3} \mathrm{SOCl} \\
363.90\end{array}$ & 35 & $147-8$ & 0.20 & 59.12 & 5.89 & 11.55 & 59.59 & 5.72 & 11.60 \\
\hline 3 & $\begin{array}{c}\mathrm{C}_{18} \mathrm{H}_{22} \mathrm{~N}_{3} \mathrm{SOCl} \\
363.90\end{array}$ & 67 & $99-100$ & 0.23 & 59.12 & 5.89 & 11.55 & 59.10 & 5.80 & 11.28 \\
\hline 4 & $\begin{array}{c}\mathrm{C}_{17} \mathrm{H}_{20} \mathrm{~N}_{3} \mathrm{SO}_{2} \mathrm{Cl} \\
365.88\end{array}$ & 62 & $175-6$ & 0.30 & 55.81 & 5.51 & 11.48 & 55.53 & 5.24 & 11.21 \\
\hline 5 & $\begin{array}{c}\mathrm{C}_{17} \mathrm{H}_{20} \mathrm{~N}_{3} \mathrm{SO}_{2} \mathrm{Cl} \\
365.88\end{array}$ & 23 & $134-5$ & 0.31 & 55.81 & 5.51 & 11.48 & 55.82 & 5.34 & 11.16 \\
\hline 6 & $\begin{array}{c}\mathrm{C}_{17} \mathrm{H}_{20} \mathrm{~N}_{3} \mathrm{SO}_{2} \mathrm{Cl} \\
365.88\end{array}$ & 56 & $177-8$ & 0.32 & 55.81 & 5.51 & 11.48 & 55.58 & 5.30 & 11.24 \\
\hline
\end{tabular}

${ }^{*} \mathrm{CHCl}_{3}: \mathrm{CH}_{3} \mathrm{OH}, 10: 1$.

TABLE 5: PA values for predicted biological activity of compounds 1-6.

\begin{tabular}{ll}
\hline Compound & Focal predicted activity $(\mathrm{PA}>0.7)$ \\
\hline $\mathbf{1}$ & Mucomembranous protector $(0.777)$ \\
& Antiviral (Influenza) $(0.711)$ \\
\hline $\mathbf{2}$ & Cardiotonic $(0.790)$ \\
& Antiviral (Influenza) $(0.704)$ \\
& Antiseborrheic $(0.768)$ \\
& Prolyl aminopeptidase inhibitor $(0.751)$ \\
\hline \multirow{3}{*}{} & Mucomembranous protector $(0.796)$ \\
& Antiviral (Influenza) $(0.711)$ \\
& Antiseborrheic $(0.780)$ \\
& Prolyl aminopeptidase inhibitor $(0.720)$ \\
\hline $\mathbf{4}$ & Antiviral (Influenza) $(0.721)$ \\
$\mathbf{5}$ & Antiviral (Influenza) $(0.711)$ \\
& Antiseborrheic $(0.768)$ \\
& Prolyl aminopeptidase inhibitor $(0.735)$ \\
\hline $\mathbf{6}$ & Mucomembranous protector $(0.712)$ \\
& Antiviral (Influenza) $(0.722)$ \\
& Antiseborrheic (0.778) \\
& Prolyl aminopeptidase inhibitor $(0.735)$ \\
\hline
\end{tabular}

3.28-3.58, and $2.22-2.33 \mathrm{ppm}$ ascribed to protons of $\mathrm{S}-$ $\mathrm{CH}_{2}, \mathrm{C}_{5}-\mathrm{CH}_{2}$ and $\mathrm{C}_{6}-\mathrm{CH}_{3}$, respectively. The HMBC of 16 shows peaks corresponding to two-bond correlations for $\mathrm{C}_{6}-\mathrm{CH}_{3} / \mathrm{C}_{6}(158.81-162.11 \mathrm{ppm})$ and three-bond correlations for $\mathrm{S}-\mathrm{CH}_{2} / \mathrm{C}_{2}(163.68-168.05 \mathrm{ppm})$ and $\mathrm{C}_{5}-\mathrm{CH}_{2} / \mathrm{C}_{4}$ (161.82-163.19 ppm).

The FT-IR spectra of $\mathbf{1 - 6}$ show absorption bands of medium intensities in the region $809-820 \mathrm{~cm}^{-1}$ assigned to $\nu \mathrm{C}-\mathrm{Cl}$ vibration as well as in the region $1035-1091 \mathrm{~cm}^{-1}$ assigned to $\delta \mathrm{C}-\mathrm{Cl}$ vibration (Table 1 ). The FT-IR spectra of 1-6 show also absorption bands in the region 2852$2864 \mathrm{~cm}^{-1}$ assigned to $v \mathrm{CH}_{2}-\mathrm{S}$ as well as in the region
$1444-1447 \mathrm{~cm}^{-1}$ assigned to $\delta \mathrm{CH}_{2}-\mathrm{S}$ vibration (Table 1). The UV/Vis spectra of $\mathbf{1}-\mathbf{6}$ show $\lambda_{\max }$ in the range $245-250$ nm (Table 1).

In the present paper the biological activity spectra were predicted for all six synthesized compounds (1-6) using PASS [12-15]. We have also selected the types of activities that were predicted for a potential compound with the highest probability (focal activities). They are presented in Table 5. According to these data the most frequently predicted types of biological activities are antiviral (Influenza), antiseborrheic, and prolyl aminopeptidase inhibitor. It ought to be pointed out that in the series of compounds 1, 3 and 6 such activity as mucomembranous protector has also been predicted, as well as in the series of compounds 2, 3, 5, and 6 such activity as prolyl aminopeptidase inhibitor.

\section{Conclusions}

The reaction of 2-thio-5-piperidinomethyl-6-methyluracil and 2-thio-5-morpholinomethyl-6-methyluracil with $o$ - $(m-$ and $p$-)chlorobenzyl chlorides in $3 \mathrm{~N} \mathrm{NaOH}$ in methanol at room temperature leads to $2-o-(m$ - and $p$ - $)$ chlorobenzylthio5-piperidinomethyl-6-methyluracils 1-3 and 2-o-( $m$ - and p-)-chlorobenzylthio-5-morpholinomethyl-6-methyluracils 4-6. The Mannich reaction of 2-o-(and $p$-) chlorobenzylthio6-methyluracils with paraformaldehyde and piperidine (or morpholine) refluxed in ethanol leads to $1,3,4$, and 6 . The results obtained by PASS method of identification of the prospective pharmacological properties of 1-6 exhibit the possibility of finding new pharmacological agents from this class of compounds.

\section{Experiment}

The purity of all described compounds was checked by melting points, TLC, and elemental analyses. Melting points (uncorrected) were determined on a Boetius microscope hot stage. Rf values refer to silica gel $\mathrm{F}_{254}$ TLC plates (Merck) 
developed with $\mathrm{CHCl}_{3}: \mathrm{CH}_{3} \mathrm{OH}(10: 1)$ and observed under UV light $(\lambda=254$ and $366 \mathrm{~nm})$. UV/Vis spectra were recorded with a SPECORD UV/Vis Spectrophotometer in methanol. IR spectra were recorded with FT-IR Bruker IFS-113 Spectrophotometer in $\mathrm{KBr}$ pellets. The ${ }^{1} \mathrm{H}$ NMR $(300 \mathrm{MHz})$ and ${ }^{13} \mathrm{C}$ NMR $(75 \mathrm{MHz})$ spectra were determined with Varian Gemini 300 spectrometer in $\mathrm{DMSO}_{d 6}$ solution at a concentration between 0.25 and $0.40 \mathrm{M}$ in the $5 \mathrm{~mm}$ sample tubes at ambient temperature. Chemical shifts are given in $\delta$ scale (ppm). Elemental analyses were performed with a Vector Euro EA 3000 analyzer.

2-thio-5-piperidinomethyl-6-methyluracil [9], 2-thio-5morpholinomethyl-6-methyl-uracil [8], and 2-o-( $m$ - and p-)chlorobenzylthio-6-methyluracils [17] have been obtained according to the literature.

The synthesis of 2-o-(and $p$-)chlorobenzylthio-5-piperidinomethyl-6-methyluracils (1 and 3 ) and 2-o-(and p-)chlorobenzylthio-5-morpholinomethyl-6-methyluracils (4 and 6 ) is as follows.

General procedure A: $0.2 \mathrm{~g}(0.8 \mathrm{mmole})$ of 2-thio5-piperidino-(morpholino-)-methyl-6-methyluracils $[8,9]$ was dissolved with stirring in room temperature in $2.5 \mathrm{~mL}$ of $3 \mathrm{~N} \mathrm{NaOH}$ in methanol. Next, to the solution $0.116 \mathrm{~mL}(0.9 \mathrm{mmole})$ of $o$-chlorobenzyl chloride or $0.146 \mathrm{~g}$ $(0.9 \mathrm{mmole})$ of $p$-chlorobenzyl chloride was added. After stirring at room temperature for 24 hours, the obtained crude product was filtered off and crystallized from methanol.

The synthesis of 2-m-chlorobenzylthio-5-piperidinomethyl-6-methyluracils (2) and 2-m-chlorobenzylthio-5morpholinomethyl-6-methyluracils (5) is as follows.

General procedure A: $0.2 \mathrm{~g}$ ( $0.8 \mathrm{mmole})$ of 2-thio-5piperidino-(morpholino-)methyl-6-methyluracils $[8,9]$ was dissolved with stirring in room temperature in $2.5 \mathrm{~mL}$ of $3 \mathrm{~N} \mathrm{NaOH}$ in methanol. Next, to the solution $0.116 \mathrm{~mL}$ $(0.9 \mathrm{mmole})$ of $m$-chlorobenzyl chloride was added. The reaction mixture was stirred in room temperature for 24 hours and after that time $5 \mathrm{~mL}$ distilled water was added. The obtained crude product was collected by filtration, washed with distilled water, and dried in the exicator. The obtained dry solid was dissolved in $10 \mathrm{~mL}$ of $\mathrm{CHCl}_{3}$ and separated by silica gel column chromatography (Merck 203-400 mesh) using the following solvent mixtures: $\mathrm{CHCl}_{3}: \mathrm{CH}_{3} \mathrm{OH} 50: 1$ $(40 \mathrm{~mL}), 40: 1(40 \mathrm{~mL}), 30: 1(30 \mathrm{~mL}), 20: 1(30 \mathrm{~mL})$, and $10: 1(20 \mathrm{~mL})$. The fractions of $20 \mathrm{~mL}$ were collected. On the basis of analytical TLC fractions of product desired were obtained by combining $20 \mathrm{~mL}$ fractions. They were concentrated on a rotary evaporator. Compounds $\mathbf{2}$ and $\mathbf{5}$ were shown to by analytically pure.

The synthesis of 2-o-(and $p$-)chlorobenzylthio-5-piperidinomethyl-6-methyluracils (1 and $\mathbf{3}$ ) and 2-o-(and $p$-)chlorobenzylthio-5-morpholinomethyl-6-methyluracils (4 and 6 ) is as follows.

General procedure B: A mixture of $0.1 \mathrm{~g}(0.38 \mathrm{mmole})$ 2-o-(or p-)-chlorobenzylthio-6-methyluracils, $0.024 \mathrm{~g}(0.4$ mmole) paraformaldehyde, and $0.0035 \mathrm{~mL}$ (0.4 mmole) morpholine (or $0.0046 \mathrm{~mL}, 0.4$ mmole piperidine) was suspended in $6 \mathrm{~mL}$ of ethanol (99.8\%) and refluxed for 8 hours. The precipitated solid was isolated by filtration, dried in room temperature, and recrystallized from methanol.

\section{References}

[1] E. De Clercq and J. Balzarini, "Knocking out human immunodeficiency virus through non-nucleoside reverse transcriptase inhibitors used as single agents or in combinations: a paradigm for the cure of AIDS?" Farmaco, vol. 50, no. 11, pp. 735-747, 1995.

[2] H. Tanaka, H. Takashima, M. Ubasawa et al., "Synthesis and antiviral activity of 6-benzyl analogs of 1[(2- hydroxyethoxy)methyl]-6-(phenylthio)thymine (HEPT) as potent and selective anti-HIV-1 agents," Journal of Medicinal Chemistry, vol. 38, no. 15, pp. 2860-2865, 1995.

[3] J. Crooks, "Thyroid and antythyroid drugs," in Side Effects of Drugs, L. Meyler and A. Herzheimer, Eds., pp. 573576, Expertia Medica, Elsevier, Amsterdam, The Netherlands, 1972.

[4] R. F. Barth, A. H. Soloway, and R. G. Fairchild, "Boron neutron capture therapy of cancer," Cancer Research, vol. 50, no. 4, pp. 1061-1070, 1990.

[5] M. F. Hawthorne, "The role of chemistry in the development of boron neutron capture therapy of cancer," Angewandte Chemie, vol. 105, pp. 997-1033, 1993.

[6] W. Tjarks and D. Gabel, "Boron-containing thiouracil derivatives for neutron-capture therapy of melanoma," Journal of Medicinal Chemistry, vol. 34, no. 1, pp. 315-319, 1991.

[7] R. A. Nugent, S. T. Schlachter, M. J. Murphy et al., "Pyrimidine thioethers: a novel class of HIV-1 reverse transcriptase inhibitors with activity against BHAP-resistant HIV," Journal of Medicinal Chemistry, vol. 41, no. 20, pp. 3793-3803, 1998.

[8] E. I. Besyadetskaya, V. G. Zubenko, L. V. Lozyuk et al., "Aminomethylated uracils, their synthesis and antiinfluenzal activity," Pharmaceutical Chemistry Journal, vol. 14, no. 7, pp. 451-456, 1980.

[9] H. R. Snyder, H. M. Foster, and G. A. Nussberger, "Mannich reactions of pyrimidines. II. 2-Methylmercapto-4-methyl-6hydroxypyrimidine and 2-thio-6-methyluracil," Journal of the American Chemical Society, vol. 76, no. 9, pp. 2441-2444, 1954.

[10] G. Bartkowiak, E. Wyrzykiewicz, G. Schroeder, A. Walkowiak, A. Szponar, and I. Pawlak, "Thio analogues of pyrimidine bases: syntheses and spectral study of new potentially biologically active 2,4-di-ortho-(meta- and para-)bromo- (chloro and nitro)-benzylthio-5-bromouracils (and 6-methyluracils)," Phosphorus, Sulfur and Silicon and the Related Elements, vol. 185, no. 7, pp. 1429-1436, 2010.

[11] T. Pospieszny and E. Wyrzykiewicz, "Thio analogs of pyrimidine bases: synthesis and spectroscopic study of new potentially biologically active disulfides of $N, O-(N, N-$ or $O, O-)$-Diand $N, N, O$-Tri- $(o-, m$-, and $p$-)bromobenzyl-2-thiouracils," Phosphorus, Sulfur and Silicon and the Related Elements, vol. 185, no. 10, pp. 2101-2107, 2010 .

[12] http:/www.ibmc.msk.ru/PASS/.

[13] V. V. Poroikov, D. A. Filimonov, YU. V. Borodina, A. A. Lagunin, and A. Kos, "Robustness of biological activity spectra predicting by computer program PASS for noncongeneric sets of chemical compounds," Journal of Chemical Information and Computer Sciences, vol. 40, no. 6, pp. 1349-1355, 2000.

[14] V. V. Poroikov and D. A. Filimonov, "How to acquire new biological activities in old compounds by computer prediction," Journal of Computer-Aided Molecular Design, vol. 16, no. 11, pp. 819-824, 2002.

[15] V. V. Poroikov and D. A. Filimonov, "PASS: prediction of biological activity spectra for substances," in Predictive Toxicology, C. Helma, Ed., pp. 459-478, Taylor \& Francis, London, UK, 2005. 
[16] T. Pospieszny and E. Wyrzykiewicz, "A practical synthesis of new S,N-disubstituted derivatives of 5-(4-methylpiperidino)methyl-2-thiouracil," Tetrahedron Letters, vol. 49, no. 36, pp. 5319-5321, 2008.

[17] E. Wyrzykiewicz and Z. Nowakowska, "Thio analogs of pyrimidine bases: syntheses and eims studies of new 2-(and 4-) $o$-( $M$ - and P-) halobenzylthio-6-methyluracils," Phosphorus, Sulfur and Silicon and Related Elements, vol. 118, no. 1-4, pp. 205-217, 1996. 


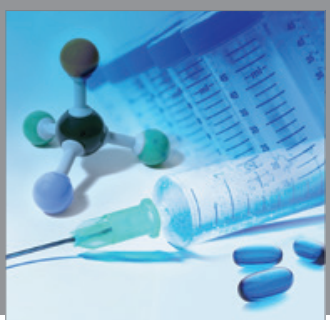

International Journal of

Medicinal Chemistry

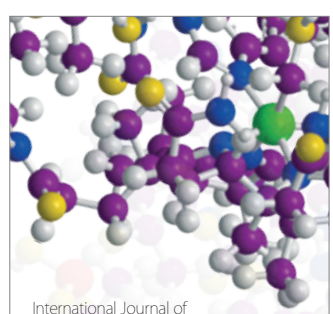

Carbohydrate Chemistry

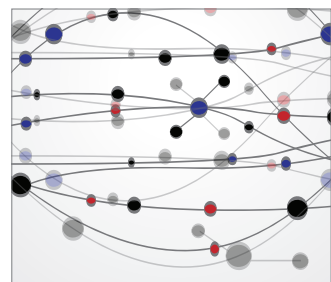

The Scientific World Journal
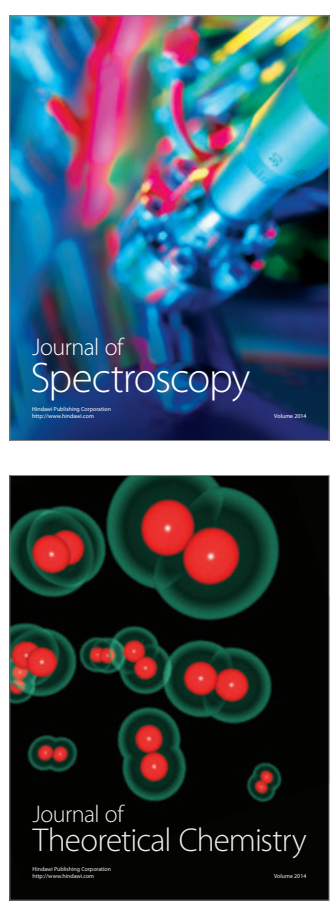
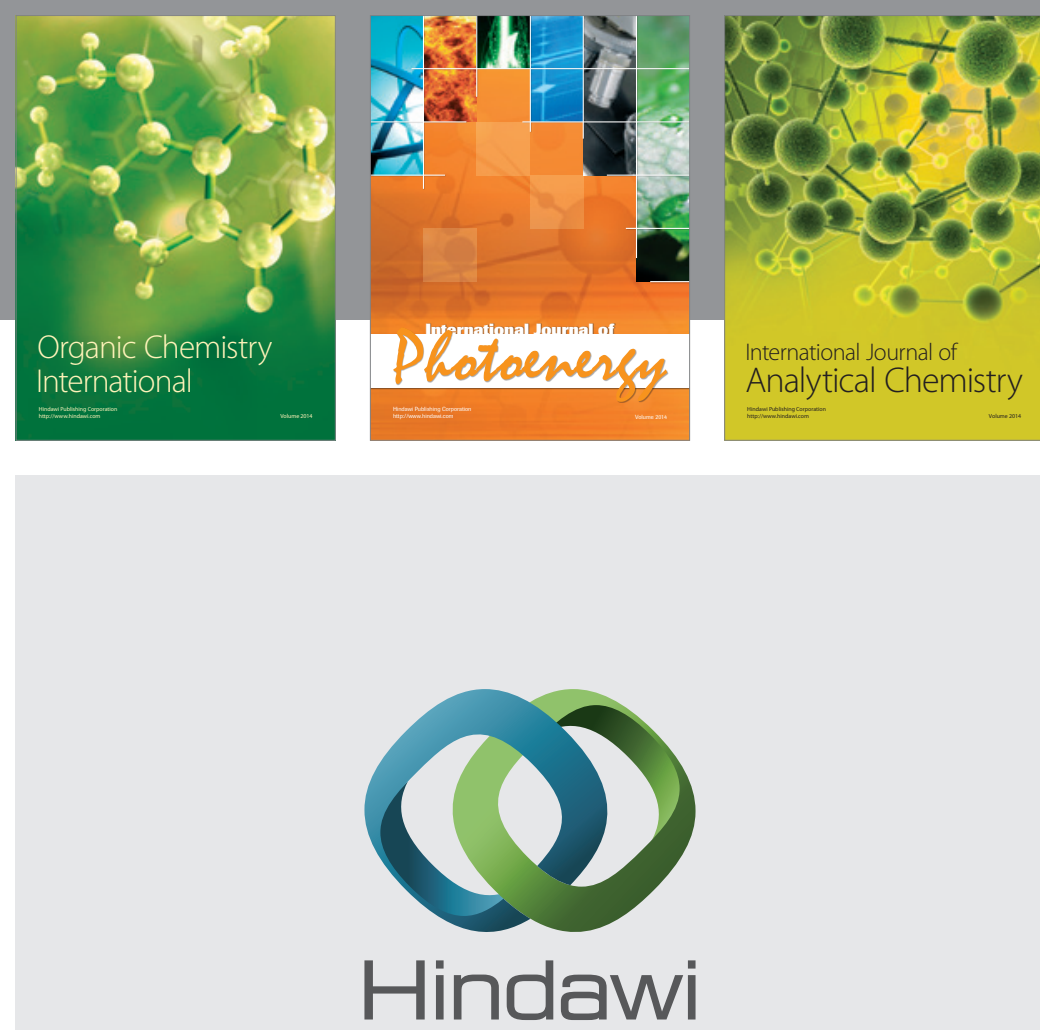

Submit your manuscripts at

http://www.hindawi.com
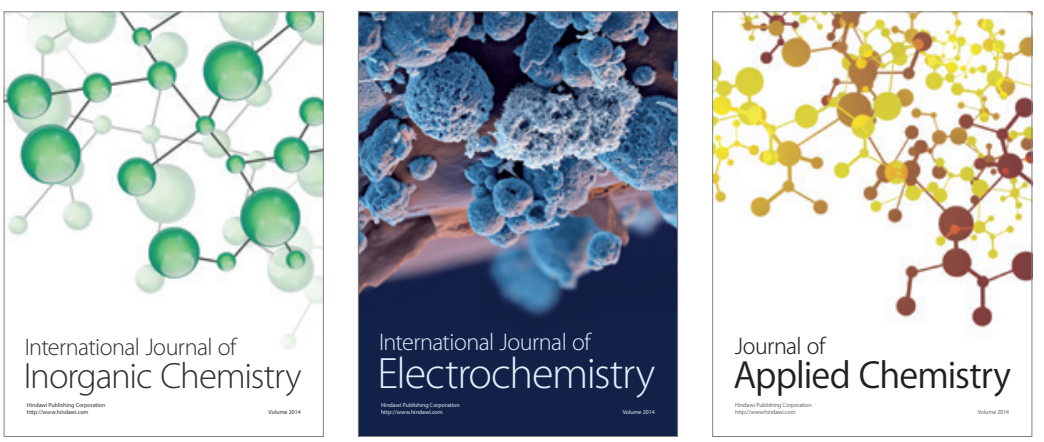

Journal of

Applied Chemistry
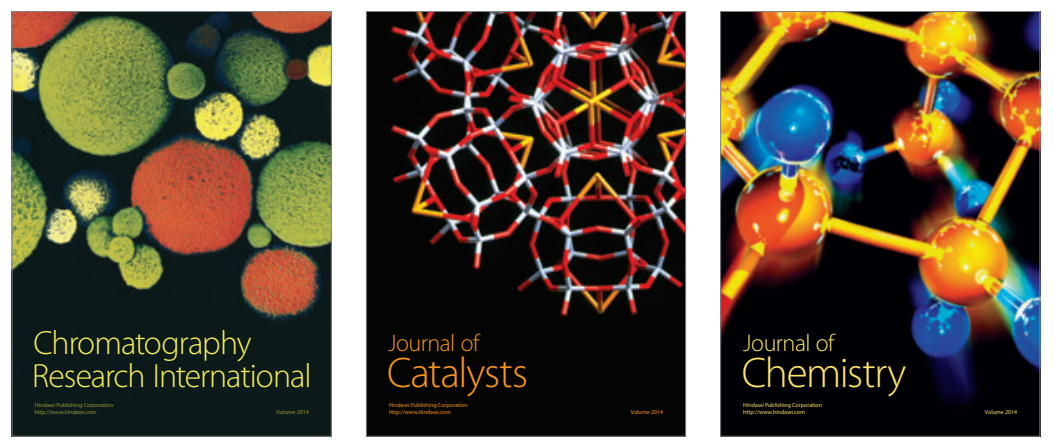
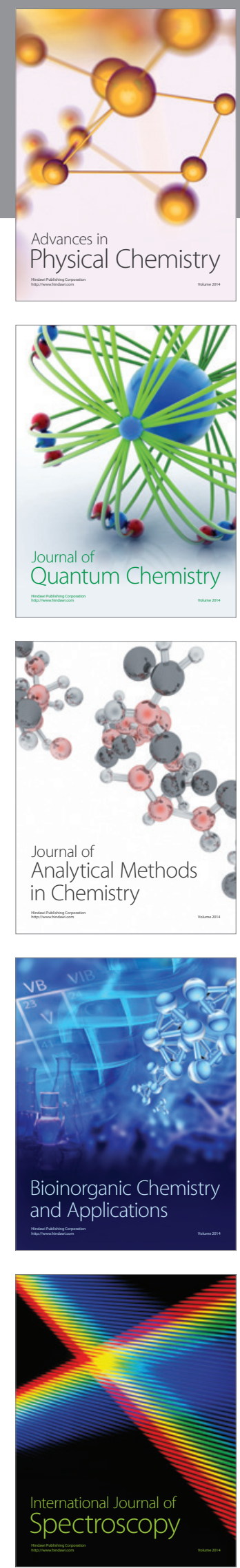